\title{
Detecção in situ de espécies reativas de oxigênio em feijoeiro tratado com extratos de Pycnoporus sanguineus e inoculado com Colletotrichum lindemuthianum*
}

\author{
Mauricele Baldo ${ }^{1}$, José Renato Stangarlin¹, Gilmar Franzener ${ }^{1}$, Lindomar Assi¹, Odair José Kuhn¹, Kátia Regina \\ Freitas Schwan-Estrada ${ }^{2}$
}

${ }^{1}$ Centro de Ciências Agrárias, Universidade Estadual do Oeste do Paraná (UNIOESTE), Campus de Marechal Cândido Rondon. Rua Pernambuco 1777, Centro. Caixa Postal 91, 85960-000, Marechal Cândido Rondon, PR, Brasil; ${ }^{2}$ Departamento de Agronomia, Universidade Estadual de Maringá (UEM), Av. Colombo 5790, CEP 87020-900, Maringá/PR. *Parte da Dissertação de Mestrado do primeiro autor

Autor para correspondência: José Renato Stangarlin (jrstangarlin@pq.cnpq.br)

Data de chegada: 22/10/2010. Aceito para publicação em: 10/10/2011.

1719

\section{RESUMO}

Baldo, M.; Stangarlin, J.R.; Franzener, G.; Assi, L.; Kuhn, O.J.; Schwan-Estrada, K.R.F. Detecção in situ de espécies reativas de oxigênio em feijoeiro tratado com extratos de Pycnoporus sanguineus e inoculado com Colletotrichum lindemuthianum. Summa Phytopathologica, v.37, n.4, p.174-179, 2011.

Este trabalho teve como objetivo detectar in situ a formação de espécies reativas de oxigênio (ERO`S), particularmente peróxido de hidrogênio $\left(\mathrm{H}_{2} \mathrm{O}_{2}\right)$ e radical superóxido $\left(\mathrm{O}_{2}{ }^{-}\right)$, em plantas de feijão tratadas com extrato aquoso de micélio e de basidiocarpo de Pycnoporus sanguineus, em concentração de $5 \%(\mathrm{p} / \mathrm{v})$, e inoculadas após 3 dias com Colletotrichum lindemuthianum. As avaliações foram realizadas às 48, 96 e $192 \mathrm{~h}$ após a inoculação (hai). Água destilada, azoxystrobin (40 mg i.a. $\left.\mathrm{L}^{-1}\right)$ e acibenzolar-S-metil (75 mg i.a. $\mathrm{L}^{-1}$ ) foram utilizados como tratamentos controle. Foi detectada formação de $\mathrm{H}_{2} \mathrm{O}_{2}$ em 48 hai apenas para o tratamento com extrato de basidiocarpo. Para $\mathrm{O}_{2}$, foi detectada a formação principalmente para o tratamento com extrato de micélio em 48 hai. Em 192 hai todos os tratamentos apresentaram reação para $\mathrm{H}_{2} \mathrm{O}_{2}$ e $\mathrm{O}_{2}$ nas células epidérmicas e do mesófilo, provavelmente em decorrência do processo infeccioso. Estes resultados indicam o potencial dos extratos de $P$. sanguineus na indução de ERO's em feijoeiro no início da infecção, o que pode contribuir para a redução da severidade de antracnose.

Palavras-chave adicionais: indução de resistência, peróxido de hidrogênio, radical superóxido.

\begin{abstract}
Baldo, M.; Stangarlin, J.R.; Franzener, G.; Assi, L.; Kuhn, O.J.; Schwan-Estrada, K.R.F. In situ detection of reactive oxygen species in bean plants treated with Pycnoporus sanguineus extracts and inoculated with Colletotrichum lindemuthianum. Summa Phytopathologica, v.37, n.4, p.174-179, 2011.
\end{abstract}

This study aimed to detect in situ the formation of reactive oxygen species (ROS), specially hydrogen peroxide $\left(\mathrm{H}_{2} \mathrm{O}_{2}\right)$ and superoxide $\left(\mathrm{O}_{2}^{-}\right)$, in bean plants treated with aqueous extracts of mycelium (AEM) and basidiocarp (AEB) from Pycnoporus sanguineus at a concentration of $5 \%(\mathrm{w} / \mathrm{v})$ and inoculated after three days with Colletotrichum lindemuthianum. Evaluations occurred at 48, 96 and 192 hours after inoculation (hai). Distilled water, azoxystrobin (40 $\mathrm{mg}$ a.i. $\left.\mathrm{L}^{-1}\right)$ and acibenzolar-S-methyl $\left(75 \mathrm{mg}^{2}\right.$ a.i. $\left.\mathrm{L}^{-1}\right)$ were used as control treatments. $\mathrm{H}_{2} \mathrm{O}_{2}$ formation within 48 hai was detected only for the treatment with basidiocarp extract. As to $\mathrm{O}_{2}{ }^{-}$, formation was detected mainly for the treatment with mycelium extract within 48 hai. At 192 hai, all treatments showed reaction for $\mathrm{H}_{2} \mathrm{O}_{2}$ and $\mathrm{O}_{2}-$ in epidermal and mesophyllic cells probably due to the infectious process. These results indicate the potential of $P$. sanguineus extracts to induce ROS formation in bean plants in early infection, which may contribute to reduce anthracnose severity.

Keywords: resistance induction, hydrogen peroxide, superoxide.

As espécies reativas de oxigênio (ERO) são moléculas reduzidas, transitórias e altamente reativas, produzidas no caminho metabólico de transformação do oxigênio molecular $\left(\mathrm{O}_{2}\right)$ a água $\left(\mathrm{H}_{2} \mathrm{O}\right)$ (16). A partir da adição de um simples elétron, o oxigênio molecular é convertido ao radical ou ânion superóxido $\left(\mathrm{O}_{2}{ }^{-}\right)$, um processo mediado, provavelmente, por peroxidases ou $\mathrm{NAD}(\mathrm{P}) \mathrm{H}$ oxidases associadas à membrana, ou mesmo por lipoxigenases a partir de ácidos graxos e $\mathrm{O}_{2}(8)$. O superóxido formado pode passar por reações de óxido-redução ou ser "dismutado" e regenerar $\mathrm{O}_{2} \mathrm{e}$ peróxido de hidrogênio $\left(\mathrm{H}_{2} \mathrm{O}_{2}\right)$, o que pode ocorrer espontaneamente em pH neutro ou pela ação da enzima superóxido dismutase. $\mathrm{O}$
$\mathrm{H}_{2} \mathrm{O}_{2}$ formado pode sofrer diferentes transformações: reduzido ao radical hidroxil $(\mathrm{OH} \cdot)$; convertido a $\mathrm{H}_{2} \mathrm{O}$ e $\mathrm{O}_{2}$ pela ação da catalase; convertido a $\mathrm{H}_{2} \mathrm{O}$ pela oxidação de moléculas substratos, como ascorbato, via peroxidases (24).

Espécies reativas de oxigênio podem se acumular rapidamente no início do processo infeccioso em ambas interações patógenohospedeiro, compatíveis ou incompatíveis, um processo conhecido como explosão oxidativa (12). Essa rápida resposta ocorre em poucos minutos depois da infecção, persistindo, no entanto, não mais do que uma hora até que retorne ao seu nível basal. A explosão oxidativa tem sido verificada em reações de hipersensibilidade em 
resposta a infecção por fungos (22) e bactérias (2). Além disso, estresses abióticos (9) e várias fitotoxinas fúngicas e bacterianas podem induzir a formação de espécies reativas de oxigênio (12).

As espécies reativas de oxigênio podem atuar de diferentes maneiras durante a resposta de resistência da planta (8): a) diretamente sobre o patógeno, inibindo seu desenvolvimento; b) fortalecendo a parede celular por favorecer a formação de ligações cruzadas com proteínas estruturais; c) peroxidação de lipídeos da membrana plasmática, fortalecendo sua integridade devido à redução da sua fluidez; d) o peróxido de hidrogęnio $\left(\mathrm{H}_{2} \mathrm{O}_{2}\right)$, a espécie reativa de oxigênio mais estável e prontamente transportada através da membrana, pode regular a expressão de genes requeridos para a ativação da resistência ou pode formar ácido jasmônico, um mensageiro secundário, a partir da atividade da enzima lipídio hidroperoxidase presente na membrana plasmática.

A detecção e quantificação de ERO em sistemas biológicos são particularmente difíceis devido à rápida destruição e detoxificação ("scavenging") desses radicais por mecanismos antioxidantes celulares. Além disso, as ERO são difíceis de serem detectadas diretamente por métodos espectrofotométricos ou HPLC. Por isso, a maioria das técnicas de detecção baseia-se na oxidação ou redução de certos compostos pelas ERO (18). Alguns métodos de detecção de ERO em plantas podem ser: macroscópico/microscópico (com nitroblue tetrazolium, amido/iodeto de potássio e cloreto de titânio); espectrofotométrico (com nitroblue tetrazolium, citocromo $\mathrm{C}$ e epinefrina); fluorescente (com piranina e escopoletina) e quimioluminescente (com luminol e luciginena) (3).

Considerando os diversos trabalhos que apontam o potencial de basidiomicetos para controle de doenças em plantas $(1,7,23)$, este trabalho foi desenvolvido com o objetivo de detectar a formação in situ das espécies reativas de oxigênio peróxido de hidrogênio e superóxido em feijoeiro tratado com extratos de basidiocarpo e de micélio de Pycnoporus sanguineus (L. ex Fr.) Murr e inoculado com Colletotrichum lindemuthianum (Sacc \& Magn.) Lams-Scrib.

\section{MATERIAL E MÉTODOS}

O patógeno foi isolado a partir de lesões em folhas de feijoeiro infectadas naturalmente com $C$. lindemuthianum, coletadas no município de Marechal Cândido Rondon, e cultivado em meio ágarvagem (17).

A obtenção do extrato bruto foi adaptada da metodologia de Assi (1). Basidiocarpos de P. sanguineus foram coletados na região Oeste do Paraná, secos em temperatura constante de $30^{\circ} \mathrm{C}$ e moídos em moinho de facas. O preparo dos extratos aquosos (EA) constituiu na hidratação do pó seco de basidiocarpos por $24 \mathrm{~h}$ a temperatura de $4{ }^{\circ} \mathrm{C}$, na proporção de $14 \mathrm{~mL}$ de água destilada para $1 \mathrm{~g}$ de pó seco de basidiocarpo, sendo em seguida filtrados em papel Whatman $\mathrm{n}^{\circ} 1$ (7). Os filtrados coletados foram submetidos a uma nova filtragem de esterilização em sistema Millipore com membrana de $0,45 \mu \mathrm{m}$ de diâmetro de poro. Esses filtrados foram armazenados em geladeira a $4{ }^{\circ} \mathrm{C}$ e diluídos para a concentração de $5 \%$.

Para obtenção do micélio de $P$. sanguineus, foram preparados $100 \mathrm{~mL}$ de meio de cultura BD (batata-dextrose) e autoclavados a $120{ }^{\circ} \mathrm{C}$ e $1 \mathrm{~atm}$ por $20 \mathrm{~min}$, para onde foram repicados cinco discos de meio de cultura contendo micélio de P. sanguineus, crescido por 14 dias em meio BDA e escuro a $25^{\circ} \mathrm{C}$. Os frascos foram mantidos em escuro sob temperatura de $25^{\circ} \mathrm{C}$, sob agitação (100 rpm) (23).
Após vinte dias, foi filtrado o conteúdo de cada frasco em papel filtro Whatman $\mathrm{n}^{\circ} 1$. O micélio retido no filtro foi colocado em estufa a $40{ }^{\circ} \mathrm{C}$ até obtenção de peso constante. O micélio foi macerado e posteriormente hidratado conforme metodologia utilizada para o extrato de basidiocarpo.

Sementes de feijoeiro (Phaseolus vulgaris L.) IAPAR 81 (Carioca), cultivadas em vasos em casa de vegetação, foram tratadas com extratos aquosos de micélio e basidiocarpo de $P$. sanguineus (5\%), azoxystrobin (40 mg i.a. $\mathrm{L}^{-1}$ ); acibenzolar-S-metil (ASM - 75 $\mathrm{mg}$ i.a. $\left.\mathrm{L}^{-1}\right)$ e água. Os extratos foram aplicados na primeira folha, três dias antes da inoculação do patógeno. A inoculação do patógeno, com suspensão de $1 \times 10^{4}$ conídios $\mathrm{mL}^{-1}$, foi realizada na primeira folha trifoliada tratada, bem como na segunda folha trifoliada não tratada, e após a inoculação as plantas foram mantidas em temperatura de $25^{\circ} \mathrm{C}$ e em câmara úmida, durante todo o período de avaliação (192 h). Após esse período as plantas foram retiradas da câmara úmida e mantidas em casa de vegetação climatizada a 25 oC até o aparecimento dos sintomas. A severidade foi estimada a cada três dias com auxílio de escala diagramática (6). Com as avaliações de severidade da doença, procedeu-se a construção da curva de progresso da doença e a determinação da área abaixo da curva de progresso da doença (AACPD) por meio de equação proposta por Campbell \& Madden (4).

As análises histológicas foram realizadas 48, 96 e $192 \mathrm{~h}$ após inoculação (hai). Três discos foliares de $0,785 \mathrm{~cm}^{2}$ de cada tratamento foram usados para as observações. A localização in situ de $\mathrm{H}_{2} \mathrm{O}_{2}$ e $\mathrm{O}_{2}-{ }^{-}$foi adaptada das metodologias adotadas por RomeroPuertas et al. (19) e Freyer et al. (10). Esses discos foliares foram imersos em solução DAB (diaminobenzidine) para localização de $\mathrm{H}_{2} \mathrm{O}_{2}$ e solução NBT (nitro blue tetrazolium) para $\mathrm{O}_{2}-$, ambas a $0,1 \%$ em tampão fosfato de sódio $50 \mathrm{mM}$ (pH 6,0). Os tecidos tratados foram infiltrados em suas respectivas soluções, em vácuo (90 mm Hg) durante dois períodos de 25 min cada. Posteriormente, os tecidos foram descolorados por imersão em etanol $\left(96^{\circ} \mathrm{GL}\right)$ aquecido a $60^{\circ} \mathrm{C}(20)$. Após a coloração, os discos foram montados em lâminas de vidro e observados em microscópio ótico. A formação de $\mathrm{H}_{2} \mathrm{O}_{2}$ foi determinada através de observação de precipitados de coloração marrom no tecido, e de $\mathrm{O}_{2}{ }^{-}$através de observação de precipitados de coloração azul no tecido.

\section{RESULTADOS E DISCUSSÃO}

Os extratos de P. sanguineus induziram a formação de espécies reativas de oxigênio. No tratamento com extrato aquoso de basidiocarpo, em 48 hai, observou-se região contendo alguns esporos germinados em que havia reações para $\mathrm{H}_{2} \mathrm{O}_{2}$ ocorrendo na parede das células epidérmicas que estavam em contato com esses conídios (Figura 1A). Para os demais tratamentos não houve reação para ERO's nos momentos iniciais (Figura 1B), mas apenas a partir de 192 hai. Para este tempo de amostragem na testemunha água, visualizou-se, em decorrência do processo infeccioso, presença de hifas, desorganização citoplasmática e colapso das células da epiderme, representado pela coloração marrom uniformemente distribuída pelo citoplasma, observadas tanto na $1^{\mathrm{a}}$ quanto na $2^{\mathrm{a}}$ folha trifoliolada (Figura 1C).

Para $\mathrm{O}_{2}^{--}$, em 48 hai, no tratamento com extrato aquoso de basidiocarpo observou-se fraca reação nas células epidérmicas (Figura 2A), enquanto que nas folhas tratadas com extrato aquoso de micélio detectou-se presença de forte reação nas células 

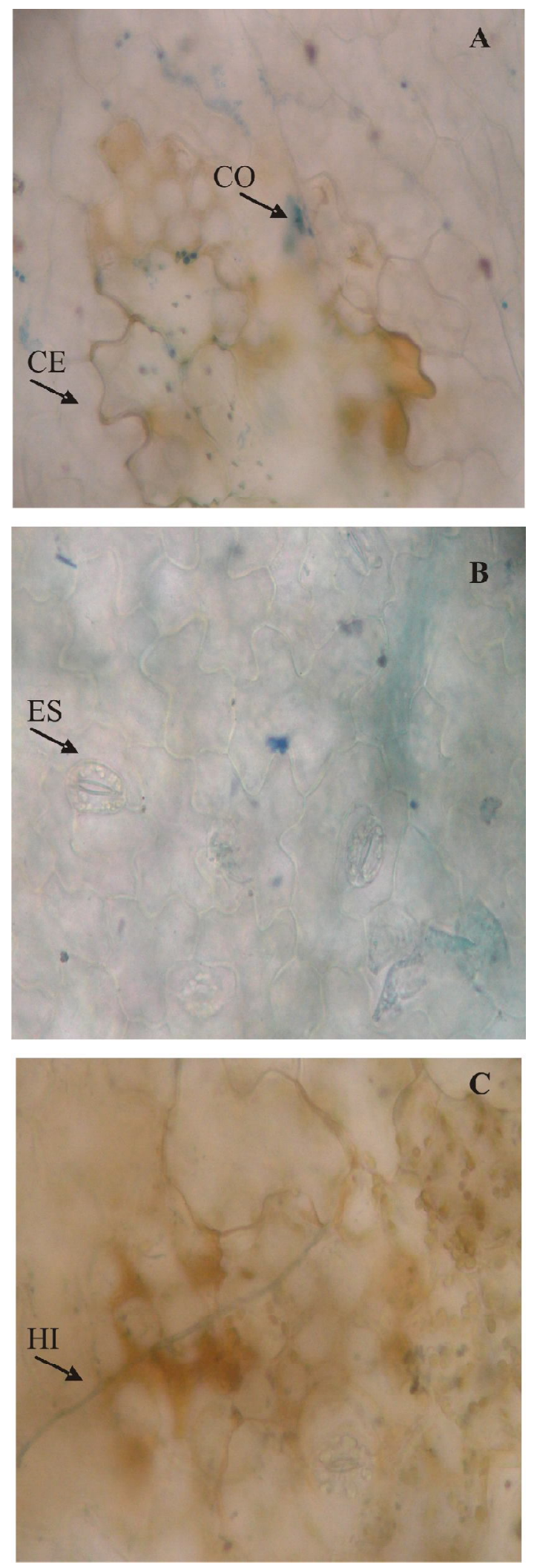

Figura 1. Formação de $\mathrm{H}_{2} \mathrm{O}_{2}$ em feijoeiro tratado com extratos aquosos de micélio e de basidiocarpo de $P$. sanguineus e inoculado com $C$. lindemuthianum. A) extrato de basidiocarpo - parede das células epidérmicas (CE) com forte deposição de $\mathrm{H}_{2} \mathrm{O}_{2}$, indicada pela coloração avermelhada, às 48 hai; B) água - ausência de formação de $\mathrm{H}_{2} \mathrm{O}_{2}$, às 96 hai; C) água colapso de células indicadas pela cor marrom uniformemente distribuída pelo citoplasma, às 144 hai. CO: conídio e HI: hifa de C. lindemuthianum. ES: estômato.
Tabela 1. Área abaixo da curva de progresso da doença (AACPD) para antracnose causada por C. lindemuthianum em feijoeiro em função dos tratamentos com extratos aquosos (EA) de basidiocarpo e micélio de cultura de P. sanguineus.

\begin{tabular}{lcc}
\hline Tratamentos $^{1}$ & \multicolumn{2}{c}{ AACPD } \\
\cline { 2 - 3 } & $\mathbf{1}^{\mathbf{2}}$ Folha $^{2}$ & $\mathbf{2}^{\mathbf{2}}$ Folha $^{2}$ \\
\hline Extrato de basidiocarpo $^{3}$ & $12,99 \mathrm{ab}^{6}$ & $8,14 \mathrm{ab}^{5}$ \\
Extrato de micélio $^{3}$ & $6,8 \mathrm{~cd}$ & $2,95 \mathrm{~d}$ \\
Água $^{6}$ & $14,93 \mathrm{a}$ & $10,44 \mathrm{a}$ \\
Fungicida $^{4}$ & $2,50 \mathrm{e}$ & $3,67 \mathrm{~cd}$ \\
ASM $^{5}$ & $4,9 \mathrm{~d}$ & $2,79 \mathrm{~d}$ \\
\hline C.V. $(\%)$ & $\mathbf{7 , 9 4}$ & $\mathbf{1 1 , 0 1}$ \\
\hline
\end{tabular}

${ }^{1}$ Tratamento realizado por aspersão três dias antes da inoculação;

${ }^{2}$ Tratamento realizado na $1^{a}$ folha; inoculação realizada nas $1^{a}$ e $2^{a}$ folhas; ${ }^{3}$ Extratos aquosos de basidiocarpo e de micélio de $P$. sanguineus em concentração de $5 \%(\mathrm{p} / \mathrm{v})$;

${ }^{4}$ Azoxystrobyn (40 mg i.a. $\left.\mathrm{L}^{-1}\right)$;

${ }^{5}$ Acibenzolar-S-metil (75 mg i. a. $\left.\mathrm{L}^{-1}\right)$;

${ }^{6}$ Médias na coluna, seguidas pela mesma letra, não diferem entre si pelo teste de Tukey ao nível de 5\% de probabilidade. Para análise estatística, os dados foram transformados em arc sen $\sqrt{(\mathrm{A} / 100) \text {. }}$

epidérmicas e do mesófilo (Figura 2B). Para ASM em 48 hai ocorreu forte reação nas células epidérmicas e do mesófilo (Figura 2C) e em 96 hai observaram-se reações fracas nas células epidérmicas e fortes nas células do mesófilo, principalmente nos cloroplastos (Figura 2D). Nos tempos 48 e 96 hai não houve formação dessa ERO nos tratamentos água e fungicida. Em 192 h.a.i. observou-se presença de reação nas células epidérmicas e do mesófilo nos tratamentos água, provavelmente em decorrência do avanço do processo infeccioso.

A formação de espécies reativas de oxigênio neste trabalho pode ter sido responsável pela redução na severidade da antracnose. Isto se deve ao fato de que a aplicação de EA de $P$. sanguineus em feijoeiro reduziu a severidade, em média, em $54 \%$ para a primeira folha trifoliolada tratada e inoculada e em $72 \%$ para a segunda folha apenas inoculada, indicando indução de resistência sistêmica (Tabela 1). Para ASM a redução média da severidade foi de até $70 \%$ e para o fungicida foi de até $76 \%$.

A explosão oxidativa é freqüentemente uma resposta muito rápida, ocorrendo no intervalo de segundos ou minutos depois do tratamento com elicitor. Isto envolve a ativação de enzimas préexistentes (12). A geração de ERO pode ocorrer em duas fases, uma inicial que se dá no intervalo de minutos após a adição do patógeno, e uma fase secundária que se inicia várias horas depois da fase inicial de infecção ou tratamento com elicitores (15).

No caso de elicitores, Levine et al. (14) estudaram a produção de $\mathrm{H}_{2} \mathrm{O}_{2}$ induzida pela incubação de células de soja com o patógeno bacteriano Pseudomonas syringae pv. glycinea (Coerper) Young, Dye \& Wilkie (Psg). O isolado Psg carregando o gene de avirulência avrC não é reconhecido pela cultivar de soja Williams 82, a qual não possui o gene de resistência Rpg3. Dessa forma, Psg(AvrC) é virulento para este genótipo de soja. Em contraste, há um rápido reconhecimento de Psg carregando o gene de avirulência avrA, 

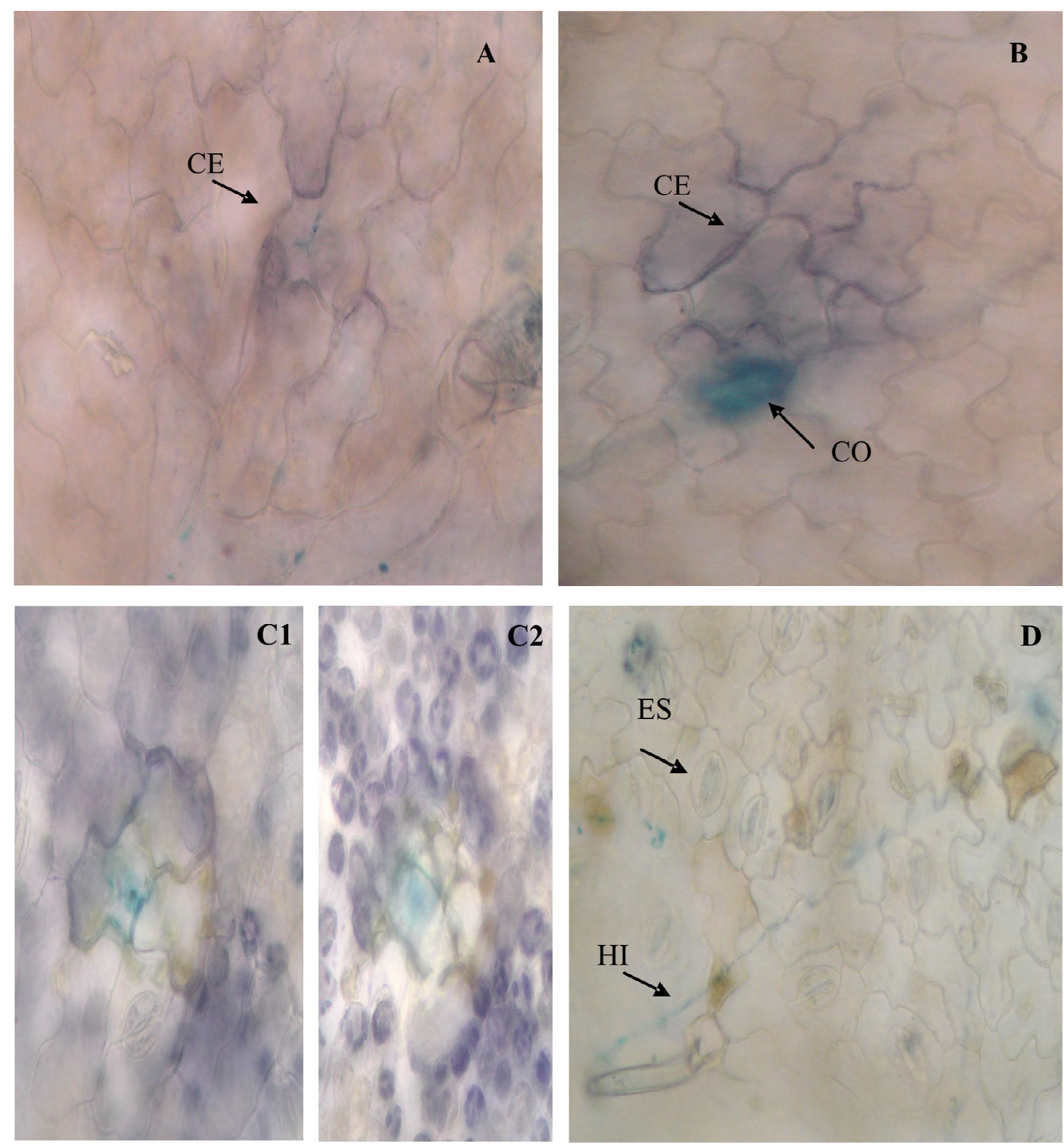

Figura 2. Formação de $\mathrm{O}_{2}{ }^{-}$em feijoeiro tratado com extratos aquosos de micélio e de basidiocarpo de P. sanguineus e inoculado com C. lindemuthianum A) extrato de basidiocarpo - parede das células epidérmicas (CE) com fraca deposição de $\mathrm{O}_{2-}^{-}$, indicada pela coloração arroxeada, às 48 hai; $\mathrm{B}$ ) extrato de micélio - parede das células epidérmicas (CE) com forte deposição de $\mathrm{O}_{2}{ }^{-}$, indicada pela coloração arroxeada, às 48 hai; C) ASM - forte reação na parede de células epidérmicas $(\mathrm{C} 1)$ e nas células do mesófilo (C2), às 48 hai; D) Fungicida - ausência de formação de $\mathrm{O}_{2}{ }^{-}$CO: conídio e HI: hifa de C. lindemuthianum. ES: estômato.

mediado pelo gene de resistência complementar Rpg2, e, dessa forma, Psg(avrA) é avirulento para a cultivar Williams 82, induzindo uma rápida resposta de hipersensibilidade em tecidos foliares inoculados. A inoculação de células de soja da cultivar Williams 82 com ambas Psg(avrA) ou Psg(avrC) conduz a uma rápida mas fraca e transitória explosão oxidativa. Nenhuma posterior produção de $\mathrm{H}_{2} \mathrm{O}_{2}$ foi observada nas células inoculadas com o isolado virulento Psg(avrC), mas, por outro lado, cerca de três horas depois da inoculação com o isolado avirulento Psg(avrA), houve uma segunda e expressiva explosão oxidativa, que se manteve por várias horas. A semelhança do que ocorreu com este isolado avirulento, o mesmo poderia ter ocorrido neste trabalho com o tratamento com os elicitores derivados de $P$. sanguineus, uma vez que os extratos de basidiocarpos e de micélio desse fungo desencadearam a geração de peróxido de hidrogênio e superóxido, o que pode ter culminado com a redução da severidade da antracnose no feijoeiro.

Essa relação entre a formação de ERO's e resistência à doença pode ser vista no trabalho de Chandra et al. (5). Esses autores trabalharam com duas culturas de suspensão de células de tomates transgênicos (+/- Pto) para produção de $\mathrm{H}_{2} \mathrm{O}_{2}$ após o desafio com dois isolados de $P$. syringae pv. tomato (Okabe) Young, Dye \& Wilkie (+/- avrPto), isoladamente. Somente quando Pto e avrPto estão presentes nos correspondentes organismos é que ocorrem duas fases distintas da explosão oxidativa. Nas remanescentes três 
interações planta-patógeno compatíveis, esses pesquisadores não observaram nenhuma explosão ou somente uma explosão inicial, indicando que a segunda explosão oxidativa está relacionada com a resistência à doença.

Outro trabalho que mostra evidências de que $\mathrm{H}_{2} \mathrm{O}_{2}$ está envolvido na resposta de resistência é o de $\mathrm{Wu}$ et al. (25). Esses autores verificaram que a expressão constitutiva de uma glicoseoxidase de Aspergillus niger Tiegh. envolvida na geração de $\mathrm{H}_{2} \mathrm{O}_{2}$ no apoplasto de plantas transgênicas de batata resultou em resistência contra a podridão bacteriana causada por Erwinia carotovora subsp. carotovora (Jones) Bergey et al., além de incrementar a resistência a Phytophthora infestans (Mont) De Bary.

Além do efeito direto tóxico sobre os patógenos, o peróxido de hidrogênio, na presença de ferro, dá origem ao radical hidroxila, extremamente reativo. Alternativamente, pode contribuir para reforçar as paredes celulares, tanto por interligações de hidroxiprolinas e glicoproteínas ricas em hidroxiprolina à matriz de polissacarídeos ou aumentando a taxa de formação de lignina por meio da atividade das peroxidases. Ambos mecanismos fazem mais resistente a parede celular à penetração do patógeno e à degradação enzimática (21). $\mathrm{O} \mathrm{H}_{2} \mathrm{O}_{2}$ também intervém na biossíntese do ácido salicílico (11), importante sinalizador nas respostas de resistência sistêmica adquirida.

Em patossistema envolvendo feijoeiro, Iriti \& Faoro (13) estudaram o envolvimento da resistência induzida por acibenzolarS-metil (ASM) contra Uromyces appendiculatus. ASM (0,3 mM) aplicado sete dias antes da inoculação do patógeno permitiu o completo controle da ferrugem, provavelmente devido ao acúmulo de peróxido de hidrogênio no apoplasto da epiderme das folhas tratadas, culminado com incremento na atividade de peroxidases e fortalecimento das paredes celulares.

Os resultados obtidos indicam que os extratos aquosos de basidiocarpo e de micélio de $P$. sanguineus possuem atividade indutora de resistência, possivelmente mediada pela formação de espécies reativas de oxigênio, particularmente peróxido de hidrogênio e superóxido, contribuindo na proteção do feijoeiro à $C$. lindemuthianum.

\section{AGRADECIMENTOS}

Os autores agradecem a Fundação Araucária e à FINEP pelo apoio financeiro na execução do projeto. JRS e KRFSE agradecem ao $\mathrm{CNPq}$ pela bolsa de produtividade em pesquisa.

\section{REFERÊNCIAS BIBLIOGRÁFICAS}

1. Assi, L. Controle de Colletotrichum lindemuthianum (Sacc. Et Magn.) Scrib. Na cultura do feijão (Phaseolus vulgaris L.) pelo extrato de Pycnoporus sanguineus (L.ex Fr.). 2005. 51f. Dissertação (Mestrado em Agronomia) - Universidade Estadual do Oeste do Paraná, Marechal Cândido Rondon.

2. Baker, C.J.; Mock, N.; Glazener, J.; Orlandi, E. Recognition responses in pathogen/non-host and race/cultivar interactions involving soybean (Glycine max) and Pseudomonas syringae pathovars. Physiological and Molecular Plant Pathology, London, v.43, p.81-94, 1993.

3. Baker, C.J.; Orlandi, E.W. Active oxygen in plant pathogenesis. Annual Review of Phytopathology, Palo Alto, v.33, p.299-321, 1995.

4. Campbell, C.L.; Madden, L.V. Introduction to plant disease epi- demiology. New York: John Wiley \& Sons, 532p. 1990.

5. Chandra, S.; Martin, G.B.; Low, P.S. The Pto kinase mediates a signaling pathway leading to the oxidative burst in tomato. Proceedings of the National Academy of Science USA, Washington, v.93, p.13393-13397, 1996.

6. Dalla Pria, M.; Silva, O.C. da.; Costa, J.L. da S.; Souza, E.D. de T; Berni, R.F. Diagnose das doenças. In: Canteri, M.G.; Dalla Pria, M.; Silva, O.C. da. Principais doenças fúngicas do feijoeiro. Ponta Grossa: UEPG, 1999. p. 18-20.

7. Di Piero, R.M.; Wulff, N.A.; Pascholati, S.F. Partial purification of elicitors from Lentinula edodes basidiocarps protecting cucumber seedling against Colletotrichum lagenarium. Brazilian Journal of Microbiology, São Paulo, v. 37, p. 169-174, 2006.

8. Doke, N.; Miura, Y.; Sanchez, L.M.; Park, H.-J.; Noritake, T.; Yoshioka, H.; Kawakita, K. The oxidative burst protects plants against pathogen attack: mechanism and role as an emergency signal for plant bio-defence - a review. Gene, Orlando-Amsterdam, v.179, p.45-51, 1996

9. Dolatabadian, A.; Jouneghani, R.S. Impact of exogenous ascorbic acid on antioxidant activity and some physiological traits of common bean subjected to salinity stress. Notulae Botanicae Horti Agrobotanici Cluj-Napoca, Cluj-Napoca, v. 37, n. 2, p. 165-172, 2009.

10. Freyer, M.; Oxborough, K.; Mullineaux, P.M.; Baker, N.R. Imaging of photo-oxidative stress response in leaves. Journal of Experimental Botany, Oxford, v.53, p.1249-1254, 2002.

11. Hammond-Kosack, K.E.; Jones, J.D.G. Responses to plant pathogens. In: Buchanan, B.B.; Gruissem, W.; Jones, R.L. (Ed.). Biochemistry and Molecular Biology of Plants. Rockville, ASPP, 2000. p. 1102-1156.

12. Heiser, I.; Oßwald, W.F. Formação e função das espécies reativas de oxigênio nas interações planta-patógeno. In: Pascholati, S.F.; Leite, B.; Stangarlin, J.R.; Cia, P. (Eds.). Interação planta-patógeno: fisiologia, bioquímica e biologia molecular. Piracicaba: FEALQ, 2008. p. 249-283.

13. Iriti, M.; Faoro, F. Benzothiadiazole (BTH) induces cell-death independent resistance in Phaseolus vulgaris against Uromyces appendiculatus. Journal of Phytopathology, Berlim, v.151, n.3, p.171-180, 2003.

14. Levine, A.; Tenhaken, R.; Dixon, R.; Lamb, C. $\mathrm{H}_{2} \mathrm{O}_{2}$ from the oxidative burst orchestrates the plant hypersensitive disease resistance response. Cell, Cambridge, v.79, p.583-593, 1994.

15. Low, P.S.; Merida, J.R. The oxidative burst in plant defense: function and signal transduction. Physiologia Plantarum, Copenhagem, v. 96, p.533-542, 1996.

16. Mehdy, M.C.; Sharma, Y.K.; Sathasivan, K.; Bays, N.W. The role of activated oxygen species in plant disease resistance. Physiologia Plantarum, Copenhagem, v.98, p.365-374, 1996

17. Rava, C.A.; Sartorato, A. Antracnose. In: Sartorato, A.; Rava, C.A. (Ed.). Principais doenças fúngicas do feijoeiro comum e seu controle. Brasília: EMBRAPA - SPI, 1994. p. 17-40.

18. Resende, M.L.V.; Salgado, S.M.L.; Chaves, Z.M. Espécies ativas de oxigênio da resposta de defesa de plantas a patógenos. Fitopatologia Brasileira, Brasília, v. 28, p. 123-130, 2003.

19. Romero-Puertas, M.C.; Rodriguez-Serrano, M.; Corpas, F.J.; Del Rio, L.A. Cadmium- induced subcellular accumulation of $\mathrm{O}_{2}{ }^{-}$and $\mathrm{H}_{2} \mathrm{O}_{2}$ in pea leaves. Plant Cell and Environment, London, v.27, p.1122-1134, 2004.

20. Stangarlin, J.R.; Osswald, W.F.; Balbi-Peña, M.I.; Franzener, G.; Becker, A. Detection of reactive oxygen species in tomato plants infected with Alternaria solani. Congresso Brasileiro de Fitopatologia, 38, Gramado, 2005. Fitopatologia Brasileira, Brasília, v.30, supl., p. 97, 2005.

21. Stangarlin, J.R. Compostos pré-formados, espécies reativas de oxigênio e fitoalexinas nas interações de resistência planta-patógeno. Summa Phytopathologica, Botucatu, v.33, supl., p.152154, 2007.

22. Vera-Estrella, R.; Blumwald, E.; Higgins, V.J. Non-specific glycopeptide elicitors of Cladosporium fulvum: evidence for involvement of active oxygen species in elicitor-induced effects on tomato cell suspensions. Physiological and Molecular Plant Patho- 
logy, London, v.42, p.9-22, 1993.

23. Viecelli, C.A.; Stangarlin, J.R.; Kuhn, O.J.; Schwan-Estrada, K.R.F. Indução de resistência em feijoeiro por filtrado de cultura de $P y c$ noporus sanguineus contra Pseudocercospora griseola. Tropical Plant Pathology, Lavras, v.34, n.2, p.87-96, 2009.

24. Wojtaszek, P. Oxidative burst: an early plant response to patho- gen infection. Biochemical Journal, London, v.322, p.681-692, 1997.

25. Wu, G.; Shortt, B.J.; Lawrence, E.B.; Levine, E.B.; Fitzsimmons, K.C.; Shah, D.M. Disease resistance conferred by expression of a gene enconding $\mathrm{H}_{2} \mathrm{O}_{2}$-generating glucose oxidase in transgenic potato plants. The Plant Cell, Rockville, v.7, p.1357-1368, 1995. 